\title{
A Comparative Study of Seminars Combined with Case-Based Learning versus Lecture-Based Learning for Cancer Pain Teaching in Medical Oncology Internship
}

\author{
Yan Yang (iD) ${ }^{1,2}$ \\ Jing-hao Yao iD ${ }^{1,2}$ \\ Ling-jie $X u^{1,3}$ \\ Zheng-guang Zhou ${ }^{1,2}$ \\ Ming-xi Wang ${ }^{1,2}$ \\ Zi-shu Wang ${ }^{1,2}$ \\ Fu-you Zhao ${ }^{1,2}$ \\ 'Department of Medical Oncology, The \\ First Affiliated Hospital of Bengbu \\ Medical College, Bengbu, Anhui, People's \\ Republic of China; ${ }^{2}$ Department of \\ Oncology, School of Clinical Medicine, \\ Bengbu Medical College, Bengbu, Anhui, \\ People's Republic of China; ${ }^{3}$ School of \\ Nursing, Bengbu Medical College, \\ Bengbu, Anhui, People's Republic of \\ China
}

Correspondence: Fu-you Zhao

Department of Medical Oncology, The

First Affiliated Hospital of Bengbu Medical

College, Bengbu, 233000, Anhui, People's

Republic of China

Tel +86 552-3086178

Email fuyouzhao@bbmc.edu.cn
Purpose: To determine whether the teaching method of seminars combined with case-based learning $(\mathrm{CBL})$ is superior to the traditional lecture-based learning (LBL) for teaching cancer pain in medical oncology internship.

Methods: Sixty medical and nursing interns in the medical oncology department of our hospital were selected between January 2019 and December 2020. Thirty students received traditional LBL instruction as the control group, and 30 students received combined seminars and CBL instruction as the observation group. The teaching evaluation and assessment was performed by theoretical and practical examinations and questionnaires.

Results: In the after-class examination, case analysis, clinical practice and overall scores of the observation group were higher than those of the control group (all $p<0.001$ ). Theoretical knowledge scores did not differ significantly between the two groups $(p=0.470)$. In the questionnaire regarding attitudes towards opioid use, the observation group had better perceptions of using opioids than the control group (all $p<0.01$ ). In the meantime, students in the observation group outperformed the control group in four aspects: self-learning $(p<0.001)$, analytical and problem-solving ( $p<0.001)$, clinical thinking $(p=0.001)$, and clinical practice $(p=0.002)$ abilities all improved, while stimulating learning interest $(p=0.184)$ and enhancing theoretical knowledge mastery ( $p=0.221$ ) were not significantly different from those of the control group. Overall, students in the observation group were more satisfied with the teaching, teaching methods and teacher performances than the control group (all $p<0.001$ ).

Conclusion: Compared to the LBL, the combination of seminars and CBL is a more effective teaching method for cancer pain management, which is worth further study.

Keywords: cancer pain teaching, seminar method, case-based learning, lecture-based learning, comparative study

\section{Introduction}

Cancer pain is a major health problem worldwide. ${ }^{1}$ It is a subjective feeling of the human to harmful stimuli, not only a physiological response but also a subjective psychological experience and is often related to somatic, psychological, spiritual and social factors. ${ }^{2}$ Cancer pain education is an important part of oncologic education, covering various aspects of theoretical and practical knowledge. In traditional teaching of cancer pain, lecture-based learning (LBL) is the basic method that teachers systematically explain theoretical knowledge while students passively listen to lectures, which 
tends to formalize the process, greatly reducing learning enthusiasm and subjective initiative. Additionally, this method is not conducive to the cultivation of basic abilities such as independent exploration, thinking and collaborative practice, often resulting in a disconnection between theoretical knowledge and clinical practice. As a result, some young clinicians or nurses have negative attitudes and insufficient knowledge about cancer pain management, incorrect concepts of opioid use, or inconsistency between theoretical knowledge and clinical practice. ${ }^{3-8}$ Therefore, optimizing the cancer pain teaching model and improving the effect of cancer pain education can not only lay the foundation for the future clinical work of medical and nursing students but also be a necessary way to improve the treatment of cancer pain patients.

The seminar teaching method is a teaching model in which students work in small groups to discuss assigned questions and issues under the guidance of teachers. ${ }^{9,10}$ It allow students to participate in discussions under the guidance of an expert, and thereby become active participants in their own learning ${ }^{11}$ and provide a variety of learning opportunities. $^{12}$ Compared with the traditional LBL method, the seminar method is distinctive for its democratic, stimulating and academic features. This method can fully exploit the academic potential of both students and teachers, deepen the understanding of research problems, and make teachers" "teaching" and students" "learning" find the best match to achieve the best teaching effect. ${ }^{13}$ Case-based learning (CBL) is a case-centered approach to teaching and learning in which teachers guide students to identify, analyze, and solve problems centering around cases. $^{14,15}$ It links theory to practice and help students being prepared for clinical practice, through the use of authentic clinical cases. $^{16}$

Though we believe seminars combined with CBL teaching method have many advantages, it may still have several shortcomings such as increasing learning burden, higher demand for student initiative and teacher competence. ${ }^{17}$ In this study, the seminar combined with CBL teaching method was used to determine whether it is superior to LBL for cancer pain teaching in medical oncology internship.

\section{Methods}

\section{Participants}

Sixty medical and nursing students who underwent internships in the Department of Medical Oncology of the First Affiliated Hospital of Bengbu Medical College from
January 2019 to December 2020 were enrolled as the study participants. Before entrance of the department, all interns had similar knowledge background of cancer pain, and received preservice training and assessment which covers general clinical medical knowledge and basic clinical operation skills. Subsequently, they were randomly divided into the seminars combined with $\mathrm{CBL}$ teaching group (observation group) and the LBL group (control group), with 30 participants in each group.

\section{Design}

All teaching contents were designed according to the syllabus and teaching plan. The Cancer Pain Diagnosis and Treatment Specification (2018 edition) ${ }^{18}$ issued by the National Health Commission, PR China, was used as the teaching material. All the teaching plans used were developed by the Department of Medical Oncology. The teachers developed specific teaching plans, selected teaching cases, and determined the teaching implementation process. All teachers were senior attending physicians or associate chief physicians. Prior to each round of teaching, six medical and six nursing interns were randomly selected among all interns, and they were further 1:1 randomly assigned to the control and observation groups within each doctor or nurse cohort. The control group used the LBL method, and the observation group used the seminars combined with CBL method. The whole teaching activity consisted of three credit hours of classroom teaching and one credit hour of teaching ward rounds and was followed by a corresponding examination. This study was approved by the Ethics Committee of the First Affiliated Hospital of Bengbu Medical College (No. BYYFY-2018KY015).

\section{LBL Group}

In the LBL group, the teachers prepared the lectures before class and composed slides. After lectures, the students accompanied the teachers who conducted teaching ward rounds. Theoretical teaching was based on the syllabus, including the mechanism and classification of cancer pain, cancer pain assessment and treatment, patient and family education and follow-up. The key points and difficulties were explained in detail to strengthen students' understanding and retention of important knowledge.

\section{Seminars Combined with CBL Group}

The observation group used seminars combined with CBL method and was divided into learning groups, with each group consisting of 5 members and 1 leader who is appointed 
by the teacher or volunteer. Each group was equipped with one teacher. The specific implementation is as follows (represented schematically in Figure 1): 1. Pre-class preparation of the teacher: The teacher determines the topic of study and discussion according to the syllabus and selects teaching cases according to the topic. The content of the topics and cases should focus on cancer pain mechanism and classification, cancer pain assessment and treatment, patient and family follow-up, etc. 2. Pre-class preparation of students: One week before the class, the teacher will distribute the topics and cases to students and provide relevant basic learning materials (Cancer Pain Diagnosis and Treatment Specification and information of cases). Students will study the basic materials, review relevant literature, discuss and communicate within the team, and the group leader will then summarize the data collected by team members and prepare the multimedia courseware. During this process, the teacher can follow up and guide, and students can also contact the teacher for questions; 3. Classroom Teaching: First, the teacher briefly introduces the topic content, conducts a simulation of the case, or leads the students to conduct teaching ward rounds. The team leader reports on the group's study of the topic and the case in the form of multimedia courseware, unresolved problems in the learning process, and the conclusions reached; other team members may make appropriate additions. After the report, the teacher and students will discuss, ask questions or make additions concerning the topic and case, and the team members will answer questions from the teachers and students. During the discussion, the teacher should guide the students to discuss in depth and control the pace of the discussion. Finally, the teacher provides a comprehensive evaluation of the presentation and discussion, systematically summarizes, answers questions, and suggests improvements.

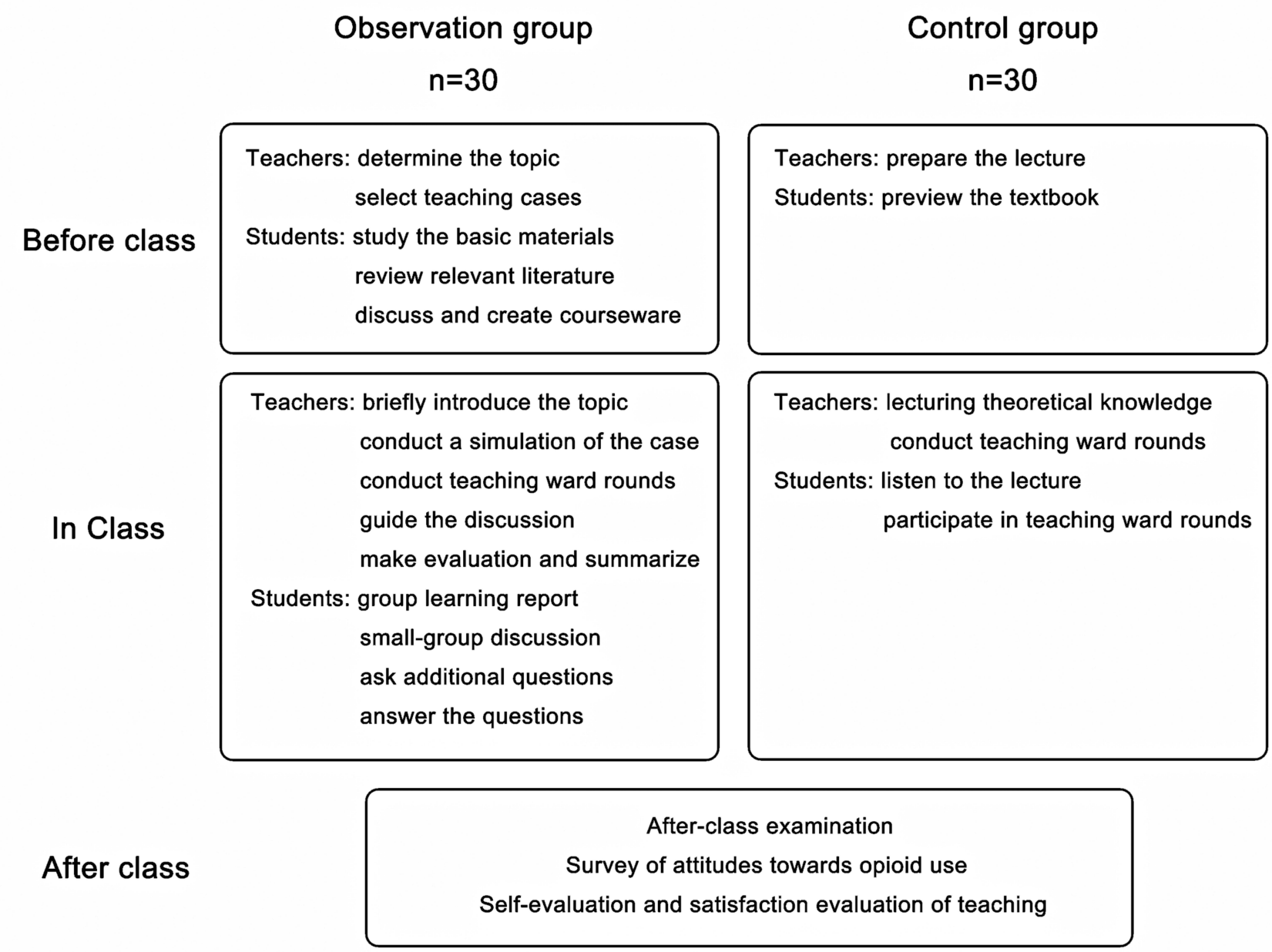

Figure I A graphical overview of the study design. 


\section{Teaching Evaluation and Assessment After-Class Examination}

After the class, an examination will be conducted, which includes three parts: theoretical knowledge, case analysis and clinical practice, with 40, 30 and 30 points, respectively, and the full score is 100 . Theoretical knowledge and case analysis are closed-book examinations that examine students' understanding and mastery of basic knowledge of cancer pain and their ability to analyze and conceptualize the diagnosis and treatment of cancer pain cases. Clinical practice is a clinical examination of typical cancer pain cases that examines the students' comprehensive ability to diagnose and treat patients in cancer pain clinical practice.

\section{Survey of Attitudes Towards Opioid Use}

A questionnaire consisting of four questions (rated from strongly disagree to strongly agree) was used to investigate students' attitudes towards opioid use. Questions are as follows: 1 . I believe opioids are harmful to the patient's health condition; 2. I am concerned about opioid addiction; 3. I am afraid of the adverse effects of opioids; 4. I consider the dosage of opioids should be lower than the required doses.

\section{Self-Evaluation and Satisfaction Evaluation}

The two groups of students evaluated the teaching methods anonymously, including the following six aspects: stimulating learning interest, improving self-learning ability, improving analytical and problem-solving ability, enhancing theoretical knowledge mastery, improving clinical thinking ability, and improving clinical practice ability. The evaluation was conducted according to these possible responses; strongly agree, agree, unsure, disagree, and strongly disagree. Students in both groups anonymously evaluated their satisfaction with teaching, including the following three aspects: overall satisfaction, satisfaction with teaching methods, and satisfaction with teachers' performance. The evaluation provided these possible responses; very satisfied, satisfied, unsure, dissatisfied, and very dissatisfied.

\section{Statistical Analysis}

Statistical analysis was performed using SPSS 24.0 (IBM Inc., USA). Numerical data are expressed as the means \pm $\mathrm{SD}$, and Student's $t$-test was used for comparisons between two groups; nonnumerical data are expressed as $[\mathrm{n}(\%)]$ and were compared using the Mann-Whitney $U$-test. Differences with $p<0.05$ were considered significant.

\section{Results}

\section{Comparison of Pre-Class Characteristics Between the Two Groups}

There are thirty students in the control group and the observation group, respectively. The mean age of the observation group was $24.2 \pm 2.5$ years old, including 12 males and 18 females; the mean age of the control group was 24.5 \pm 2.7 years old, including 13 males and 17 females. Both groups completed preservice training and assessment $(80.8 \pm 8.0$ vs $81.2 \pm 8.1$ points), and there were no significant differences in age, sex, or preservice training scores (all $p>0.05$ ).

\section{Comparison of After-Class Examination Scores Between the Two Groups}

Case analysis, clinical practice and overall scores were higher in the observation group than in the control group (25.2 \pm 2.7 vs $21.2 \pm 2.9 ; 25.1 \pm 2.1$ vs $20.8 \pm 2.9 ; 84.5 \pm 5.0$ vs $75.7 \pm 5.1$; all $p<0.001$, Table 1, Figure 2B-D). Theoretical knowledge scores were not significantly different between the two groups ( $34.3 \pm 2.5$ vs $33.6 \pm 4.4, p=0.470$, Table 1, Figure $2 \mathrm{~A}$ ).

\section{Comparison of Attitudes Towards Opioid Use Between the Two Groups}

Among the four questions about attitudes towards opioid use, the control group had more misconceptions (question 1), was more concerned about addiction (question 2), was more afraid of adverse effects (question 3 ) and was more cautious in the amount of opioid dosage (question 4) (all $p<0.01$, Table 2, Figure 3).

Table I Comparison of After-Class Examination Scores Between the Two Groups (Score, $\bar{x} \pm s$ )

\begin{tabular}{|l|c|c|c|c|}
\hline Elements & Observation Group $(\mathbf{n}=\mathbf{3 0})$ & Control Group $(\mathbf{n}=\mathbf{3 0})$ & $\boldsymbol{t}$ Value & $\boldsymbol{p}$ value \\
\hline Theoretical knowledge & $34.3 \pm 2.5$ & $33.6 \pm 4.4$ & 0.728 & 0.470 \\
Case analysis & $25.2 \pm 2.7$ & $21.2 \pm 2.9$ & 5.424 & $<0.001$ \\
Clinical practice & $25.1 \pm 2.1$ & $20.8 \pm 2.9$ & 6.474 & $<0.001$ \\
Overall scores & $84.5 \pm 5.0$ & $75.7 \pm 5.1$ & 6.814 & $<0.001$ \\
\hline
\end{tabular}



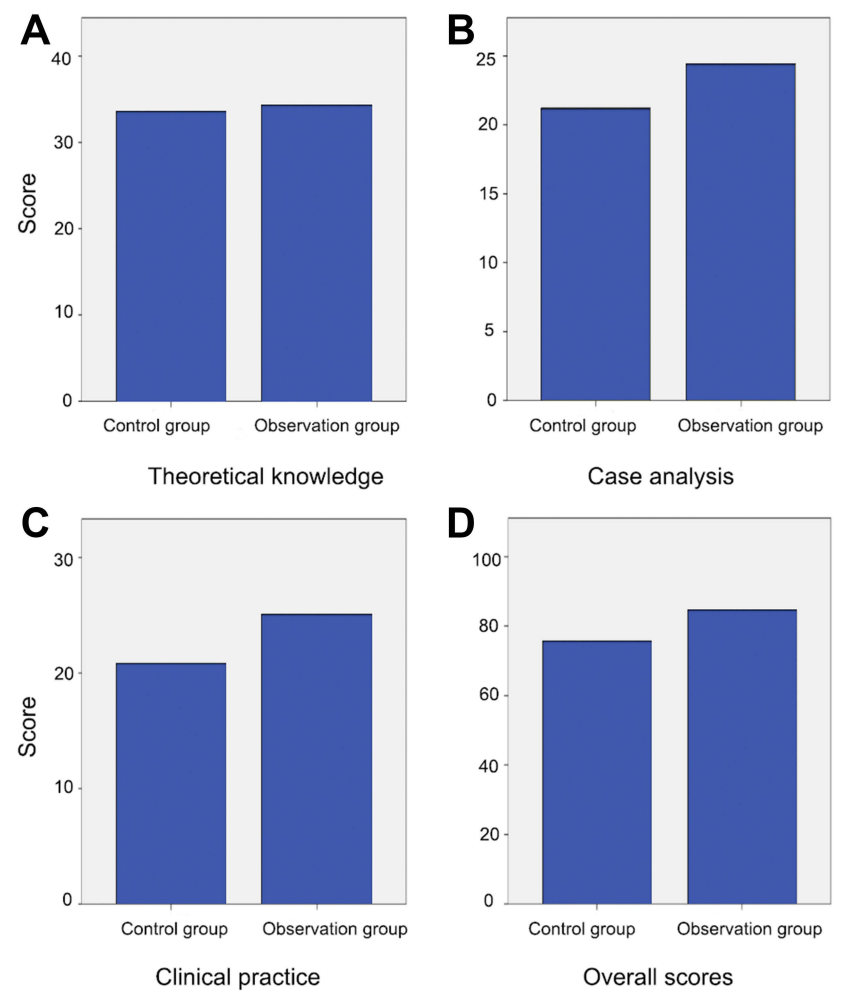

Figure 2 Comparison of after-class examination scores between the two groups. (A) Theoretical knowledge scores of the control and observation groups; (B) Case analysis scores of the control and observation groups; (C) Clinical practice scores of the control and observation groups; (D) Overall scores of the control and observation groups.

\section{Comparison of Self-Evaluation Between the Two Groups}

The students in the observation group were better than the control group in the four aspects of improving self-learning ability $(p<0.001)$, improving analytical and problem-solving ability $(p<0.001)$, improving clinical thinking ability $(p=0.001)$, and improving clinical practice ability $(p=0.002)$. In terms of stimulating learning interest $(p=0.184)$ and enhancing theoretical knowledge $(p=0.221)$, no significant difference was found between the two groups (Table 3, Figure 4). As shown in Figure 5, compared with the control group, students in the observation group who chose

Table 2 Comparison of Attitudes Toward Opioids Use Between the Two Groups [n (\%)]

\begin{tabular}{|c|c|c|c|c|c|c|c|c|}
\hline Elements & Group & $\begin{array}{c}\text { Strongly } \\
\text { Agree }\end{array}$ & Agree & Unsure & Disagree & $\begin{array}{l}\text { Strongly } \\
\text { Disagree }\end{array}$ & Z Value & $p$ value \\
\hline $\begin{array}{l}\text { I believe opioids are harmful to the } \\
\text { patient's condition }\end{array}$ & $\begin{array}{l}\text { OG } \\
\mathrm{CG}\end{array}$ & $\begin{array}{c}\text { I (3.3) } \\
8(26.7)\end{array}$ & $\begin{array}{c}2(6.7) \\
3(10.0)\end{array}$ & $\begin{array}{l}3(10.0) \\
7(23.3)\end{array}$ & $\begin{array}{l}9(30.0) \\
6(20.0)\end{array}$ & $\begin{array}{l}\text { I5 (50.0) } \\
6(20.0)\end{array}$ & -3.222 & 0.001 \\
\hline I am concerned about opioid addiction & $\begin{array}{l}\text { OG } \\
\text { CG }\end{array}$ & $\begin{array}{c}\text { I (3.3) } \\
\text { I2(40.0) }\end{array}$ & $\begin{array}{l}\text { I (3.3) } \\
6(20.0)\end{array}$ & $\begin{array}{l}7(23.3) \\
4(13.3)\end{array}$ & $\begin{array}{c}13(43.3) \\
4(13.3)\end{array}$ & $\begin{array}{l}8(26.7) \\
4(13.3)\end{array}$ & -3.743 & $<0.001$ \\
\hline $\begin{array}{l}\text { I am afraid of the adverse effects of } \\
\text { opioids }\end{array}$ & $\begin{array}{l}\text { OG } \\
\mathrm{CG}\end{array}$ & $\begin{array}{l}\text { I (3.3) } \\
3(10.0)\end{array}$ & $\begin{array}{l}2(6.7) \\
7(23.3)\end{array}$ & $\begin{array}{l}7(23.3) \\
I I(36.7)\end{array}$ & $\begin{array}{l}15(50.0) \\
7(23.3)\end{array}$ & $\begin{array}{l}5(16.7) \\
2(6.7)\end{array}$ & -2.861 & 0.004 \\
\hline $\begin{array}{l}\text { I prefer lower doses of opioids than } \\
\text { required }\end{array}$ & $\begin{array}{l}\text { OG } \\
\text { CG }\end{array}$ & $\begin{array}{l}2(6.7) \\
4(13.3)\end{array}$ & $\begin{array}{c}0(0) \\
5(16.7)\end{array}$ & $\begin{array}{c}8(26.7) \\
10(33.3)\end{array}$ & $\begin{array}{l}12(40.0) \\
8(26.7)\end{array}$ & $\begin{array}{l}8(26.7) \\
3(10.0)\end{array}$ & -2.608 & 0.009 \\
\hline
\end{tabular}

Abbreviations: OG, observation group; CG, control group. 

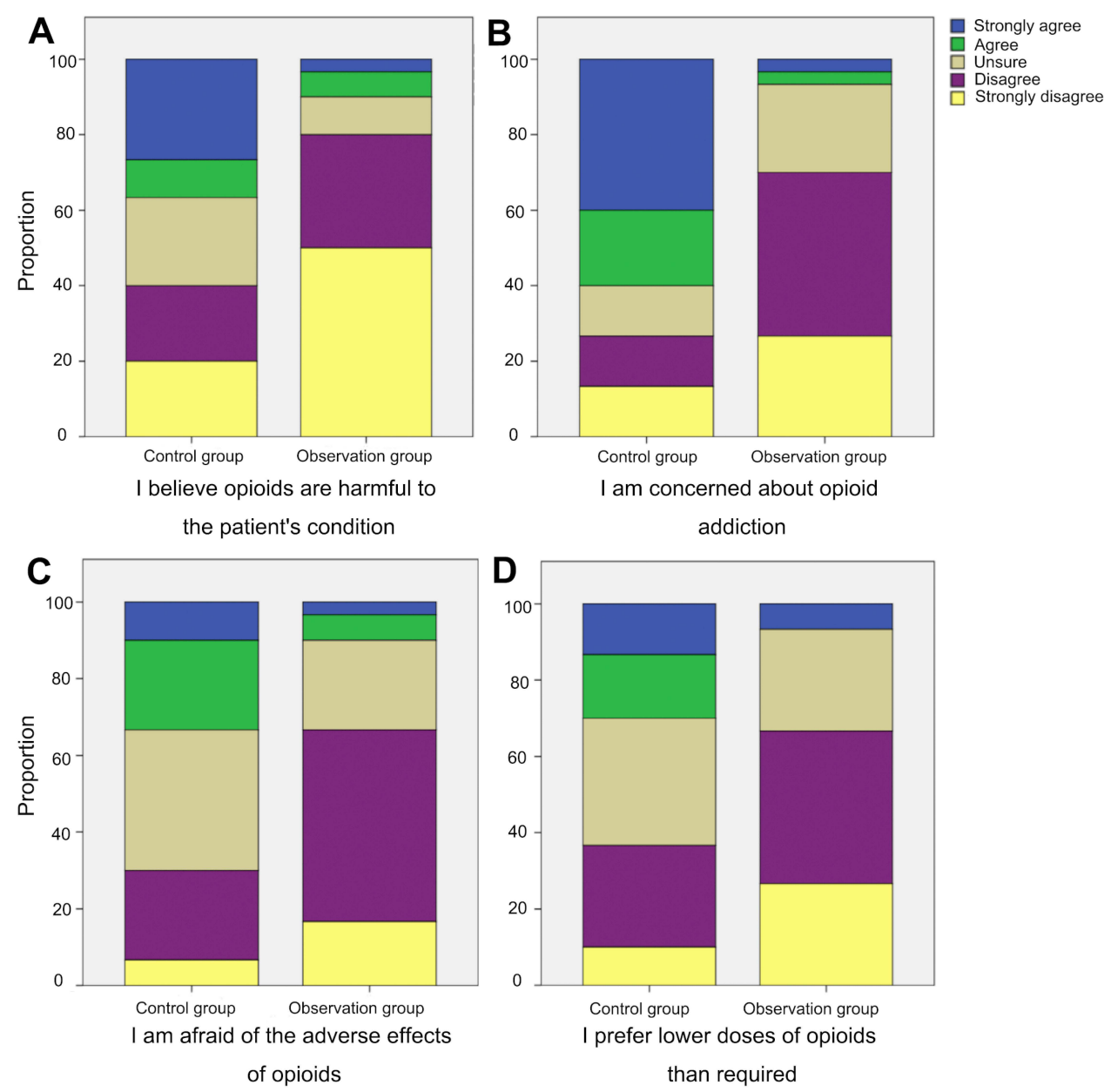

Figure 3 Comparison of attitudes toward opioids use between the two groups. (A) Proportion of different degree of agreement on "I believe opioids are harmful to the patient's condition" in the control and observation groups; (B) Proportion of different degree of agreement on "I am concerned about opioid addiction" in the control and observation groups; (C) Proportion of different degree of agreement on "I am afraid of the adverse effects of opioids" in the control and observation groups; (D) Proportion of different degree of agreement on "I prefer lower doses of opioids than required" in the control and observation groups.

the responses of strong agreement and agreement in improving clinical thinking and clinical practice ability could achieve better performance in case analysis and clinical practice examinations.

\section{Comparison of Student Satisfaction Between the Two Groups}

The overall satisfaction of teaching, satisfaction with teaching method and satisfaction with teacher performance in the observation group were higher than those in the control group (all $p<0.001$, Table 4, Figure 6).

\section{Discussion}

Due to the perception that seminars combined with the CBL teaching method have advantages in achieving the integration of basic theory, clinical thinking and practical skills, ${ }^{10,16}$ we designed this study to determine whether the combined teaching approach of seminars with $\mathrm{CBL}$ is superior to traditional LBL in cancer pain education. Based on the findings, the results showed that students in the observation group performed significantly better in after-class examination in terms of case analysis and clinical practice. Similar to this study, Liu et al ${ }^{19}$ and Zhang et $\mathrm{al}^{20}$ also found that seminars combined with $\mathrm{CBL}$ method could improve students' case analysis and clinical practice scores in different disciplines. In addition to the examination, in the comparison of student attitudes towards opioid use between the two groups, we can also see that students who received LBL method had more misconceptions, were more concerned about addiction, more afraid of adverse effects and more cautious in the 
Table 3 Comparison of Self-Evaluation Between the Two Groups [n (\%)]

\begin{tabular}{|c|c|c|c|c|c|c|c|c|}
\hline Elements & Group & Strongly Agree & Agree & Unsure & Disagree & Strongly Disagree & $Z$ Value & $p$ value \\
\hline Stimulating learning interest & $\begin{array}{l}\text { OG } \\
\text { CG }\end{array}$ & $\begin{array}{l}6(20.0) \\
5(16.7)\end{array}$ & $\begin{array}{l}17(56.7) \\
13(43.3)\end{array}$ & $\begin{array}{l}4(13.3) \\
5(16.7)\end{array}$ & $\begin{array}{l}2(6.7) \\
1(3.3)\end{array}$ & $\begin{array}{l}1(3.3) \\
6(20.0)\end{array}$ & -1.328 & 0.184 \\
\hline Improving self-learning ability & $\begin{array}{l}\mathrm{OG} \\
\mathrm{CG}\end{array}$ & $\begin{array}{c}14(46.7) \\
2(6.7)\end{array}$ & $\begin{array}{l}\text { II (36.7) } \\
8(26.7)\end{array}$ & $\begin{array}{l}3(10.0) \\
9(30.0)\end{array}$ & $\begin{array}{l}2(6.7) \\
8(26.7)\end{array}$ & $\begin{array}{c}0(0) \\
3(10.0)\end{array}$ & -4.285 & $<0.001$ \\
\hline $\begin{array}{l}\text { Improving analytical and } \\
\text { problem-solving ability }\end{array}$ & $\begin{array}{l}\text { OG } \\
\text { CG }\end{array}$ & $\begin{array}{c}16(53.3) \\
2(6.7)\end{array}$ & $\begin{array}{l}\text { II (36.7) } \\
8(26.7)\end{array}$ & $\begin{array}{l}2(6.7) \\
8(26.7)\end{array}$ & $\begin{array}{l}\text { I (3.3) } \\
8(26.7)\end{array}$ & $\begin{array}{c}0(0) \\
4(13.3)\end{array}$ & -4.867 & $<0.001$ \\
\hline $\begin{array}{l}\text { Enhancing theoretical } \\
\text { knowledge mastery }\end{array}$ & $\begin{array}{l}\mathrm{OG} \\
\mathrm{CG}\end{array}$ & $\begin{array}{l}9(30.0) \\
2(6.7)\end{array}$ & $\begin{array}{l}13(43.3) \\
21(70.0)\end{array}$ & $\begin{array}{l}5(16.7) \\
3(10.0)\end{array}$ & $\begin{array}{l}2(6.7) \\
1(3.3)\end{array}$ & $\begin{array}{l}\text { I (3.3) } \\
3(10.0)\end{array}$ & -1.224 & 0.221 \\
\hline $\begin{array}{l}\text { Improving clinical thinking } \\
\text { ability }\end{array}$ & $\begin{array}{l}\mathrm{OG} \\
\mathrm{CG}\end{array}$ & $\begin{array}{c}12(40.0) \\
1(3.3)\end{array}$ & $\begin{array}{l}7(23.3) \\
7(23.3)\end{array}$ & $\begin{array}{l}7(23.3) \\
12(40.0)\end{array}$ & $\begin{array}{l}4(13.3) \\
5(16.7)\end{array}$ & $\begin{array}{c}0(0) \\
5(16.7)\end{array}$ & -3.420 & 0.001 \\
\hline $\begin{array}{l}\text { Improving clinical practice } \\
\text { ability }\end{array}$ & $\begin{array}{l}\text { OG } \\
\text { CG }\end{array}$ & $\begin{array}{l}13(43.3) \\
3(10.0)\end{array}$ & $\begin{array}{l}11(36.7) \\
10(33.3)\end{array}$ & $\begin{array}{l}3(10.0) \\
14(46.7)\end{array}$ & $\begin{array}{l}3(10.0) \\
1(3.3)\end{array}$ & $\begin{array}{c}0(0) \\
2(6.7)\end{array}$ & -3.091 & 0.002 \\
\hline
\end{tabular}

Abbreviations: OG, observation group; CG, control group.

use of opioid dosages. This reflects that when receiving traditional education based on LBL, students tend to form negative perceptions about cancer pain and have more difficulty quickly applying what they have learned to clinical practice. To clarify in which aspects the seminars combined with CBL method is better than the traditional

\section{A}

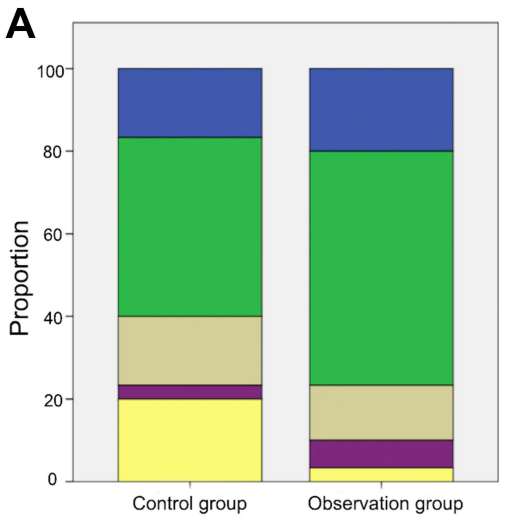

Stimulating learning interest

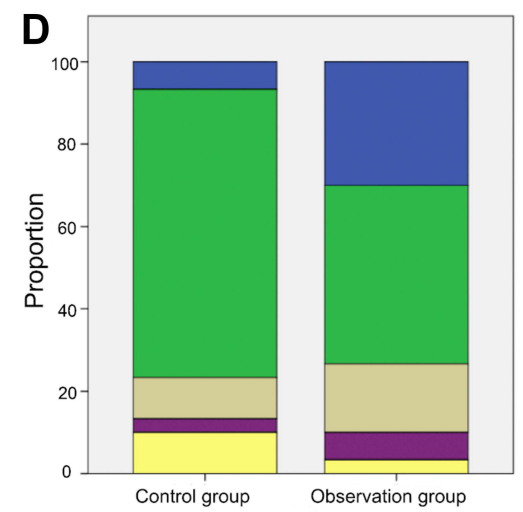

Enhancing theoretical knowledge mastery

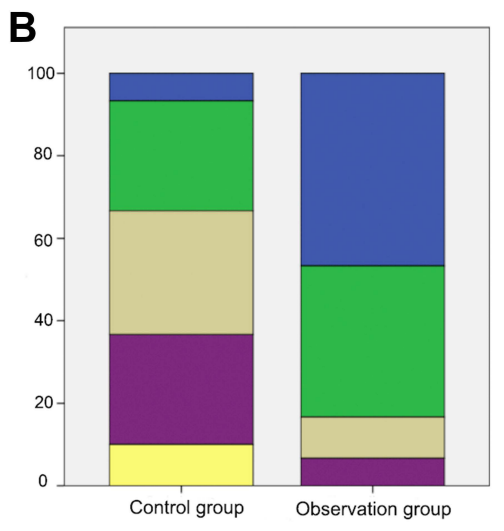

Control group Observation group
Improving self-learning ability

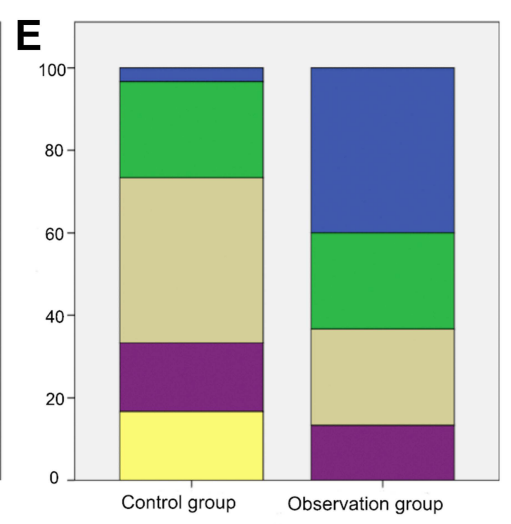

Improving clinical thinking ability

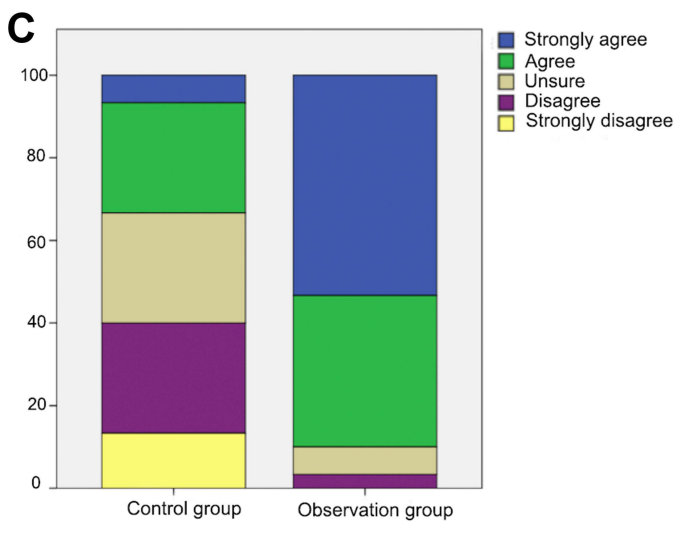

Improving analytical and problem-solving ability

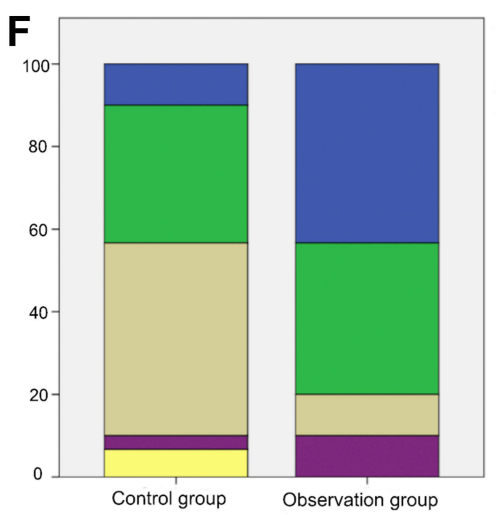

Improving clinical practice ability

Figure 4 Comparison of self-evaluation between the two groups. (A) Proportion of different degree of agreement on stimulating learning interest in the control and observation groups; (B) Proportion of different degree of agreement on improving self-learning ability in the control and observation groups; (C) Proportion of different degree of agreement on improving analytical and problem-solving ability in the control and observation groups; (D) Proportion of different degree of agreement on enhancing theoretical knowledge mastery in the control and observation groups; (E) Proportion of different degree of agreement on improving clinical thinking ability in the control and observation groups; (F) Proportion of different degree of agreement on improving clinical practice ability in the control and observation groups. 

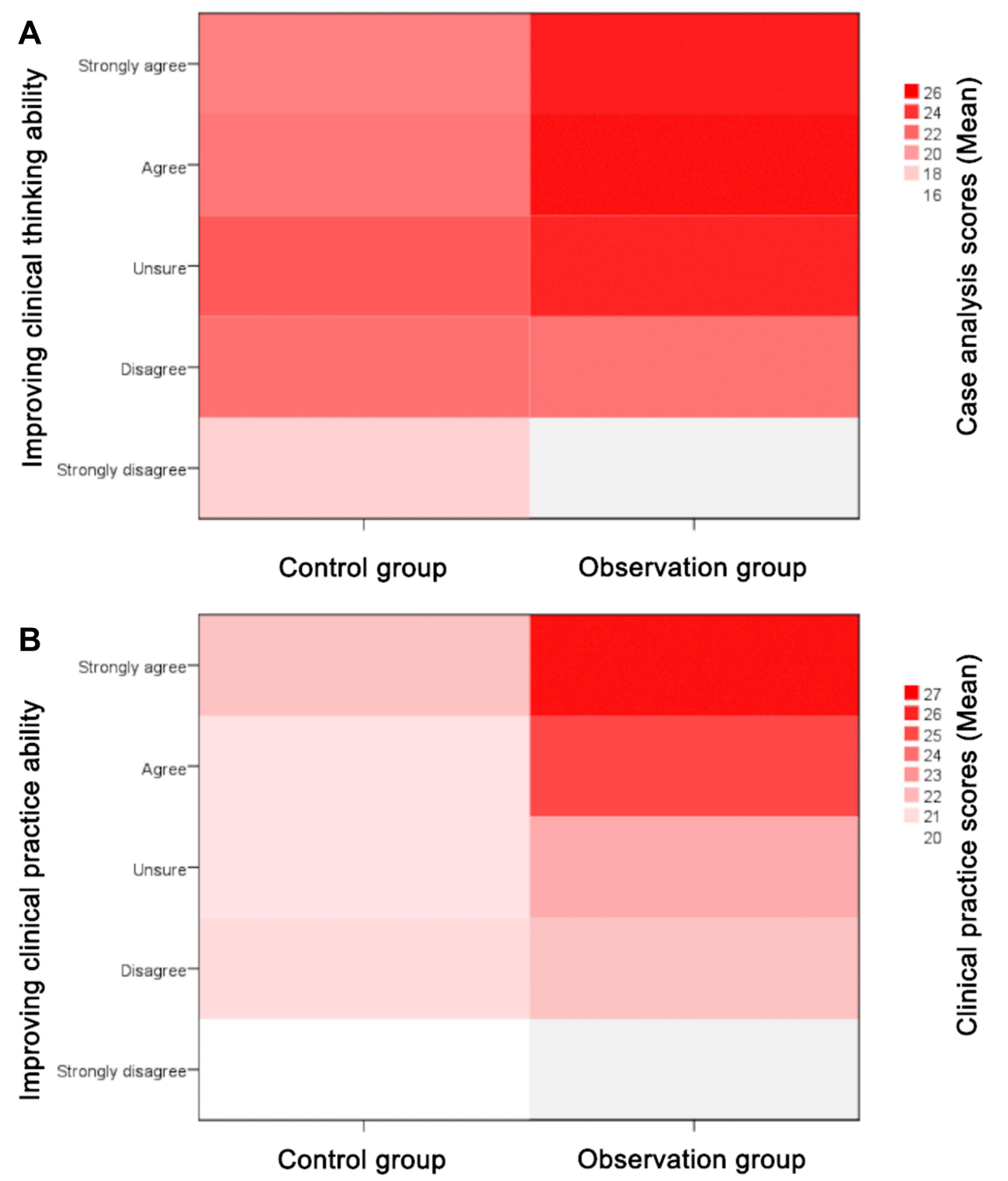

Figure 5 Hierarchical cluster analysis of the scores for the indicated items in after-class examination among students in the two groups that showed different perceptions of self-evaluation. (A) The heat map of the clinical case analysis performance of students given different evaluations in the item of improving clinical thinking ability; (B) The heat map of the clinical practice performance of students given different evaluations in the item of improving clinical practice ability.

LBL method, we required the students in both groups to complete a self-evaluation questionnaire. We found that significantly more students (strongly agreed and agreed) in the observation group than in the control group believed that the teaching method could improve self-learning, analytical and problem-solving skills, clinical thinking and clinical practice ability. Using heat maps, we found that students in the observation group who strongly agreed and agreed in improving clinical thinking and clinical practice skills could achieve better results in the examinations of case analysis and clinical practice, respectively. Therefore, the combined teaching approach may lead to better performance of students in the examination of case analysis and clinical practice by improving students' clinical thinking and clinical practice ability.

Seminars combined with CBL as a new teaching model may still face many difficulties. ${ }^{17}$ From the perspective of students, the workload of mounting literature review and self-directed and collaborative learning before class may increase the learning burden and even generate resistance among some students; the limited depth and breadth of student knowledge may affect their understanding of the topic; some students are accustomed to the indoctrination type of education, and their initiative is not strong enough to 
Table 4 Comparison of Student Satisfaction Between the Two Groups [n (\%)]

\begin{tabular}{|c|c|c|c|c|c|c|c|c|}
\hline Elements & Group & $\begin{array}{c}\text { Very } \\
\text { Satisfied }\end{array}$ & Satisfied & Unsure & Dissatisfied & $\begin{array}{c}\text { Very } \\
\text { Dissatisfied }\end{array}$ & Z Value & $p$ value \\
\hline Overall satisfaction & $\begin{array}{l}\text { OG } \\
\text { CG }\end{array}$ & $\begin{array}{l}16(53.3) \\
\text { I (3.3) }\end{array}$ & $\begin{array}{l}9(30.0) \\
9(30.0)\end{array}$ & $\begin{array}{c}5(16.7) \\
12(40.0)\end{array}$ & $\begin{array}{c}0(0) \\
7(23.3)\end{array}$ & $\begin{array}{c}0(0) \\
I(3.3)\end{array}$ & $-4.80 \mathrm{I}$ & $<0.001$ \\
\hline $\begin{array}{l}\text { Satisfaction with teaching } \\
\text { methods }\end{array}$ & $\begin{array}{l}\text { OG } \\
\text { CG }\end{array}$ & $\begin{array}{c}19(63.3) \\
0(0)\end{array}$ & $\begin{array}{l}8(26.7) \\
9(30.0)\end{array}$ & $\begin{array}{c}2(6.7) \\
13(43.3)\end{array}$ & $\begin{array}{c}I(3.3) \\
5(16.7)\end{array}$ & $\begin{array}{c}0(0) \\
3(10.0)\end{array}$ & -5.499 & $<0.001$ \\
\hline $\begin{array}{l}\text { Satisfaction with teachers' } \\
\text { performance }\end{array}$ & $\begin{array}{l}\text { OG } \\
\text { CG }\end{array}$ & $\begin{array}{l}\text { I5 }(50.0) \\
\text { I (3.3) }\end{array}$ & $\begin{array}{l}7(23.3) \\
8(26.7)\end{array}$ & $\begin{array}{l}6(20.0) \\
\text { II (36.7) }\end{array}$ & $\begin{array}{l}2(6.7) \\
7(23.3)\end{array}$ & $\begin{array}{c}0(0) \\
3(10.0)\end{array}$ & -4.172 & $<0.001$ \\
\hline
\end{tabular}

Abbreviations: OG, observation group; CG, control group.

do adequate pre-course preparation. In terms of teachers, the new teaching mode requires them to have not only rich clinical knowledge but also strong facilitation ability, encourage every student to take the initiative to acquire knowledge, be good at identifying problems from student views and comments, give reasonable answers and summaries, and guarantee the smooth progress of the course. Therefore, it is urgent for them to evaluate how to optimize teaching skills, course design and course administration to allow for this new teaching model to display its best effects. In this study, the teaching setting of cancer pain education was chosen for the following reasons: the content of cancer pain management is moderate, so that students are not easily overburdened in preparation, which may affect their motivation; cancer pain-related concepts are close to daily life, and easy to understand; cancer pain management is more focused on practical mastery, which relies on student subjective initiative and collaborative practice ability; cancer pain is a high incidence event in the clinical practice of medical oncology, which means teachers usually have rich clinical experiences and are able to provide clear guidance to students from their personal experience. In this study, we found that students in the observation group showed more satisfaction in overall teaching, teaching methods and teachers' performance than those in the control group. Considering the improvement in identifying perceived concerns about and barriers to pain control, student learning performance, and acceptance of teaching, we hypothesize that cancer pain education may be a dominant teaching scenario for the combined teaching approach of seminars and CBL.

There may be some possible limitations in this study. Due to the teaching schedule required by the Teaching and Research Office, it was not possible to assign the same teacher to teach LBL group and seminars combined with CBL group in this study, so the teaching differences between teachers may still affect the results of the study. Therefore, each teacher selected for this study had similar teaching experience and
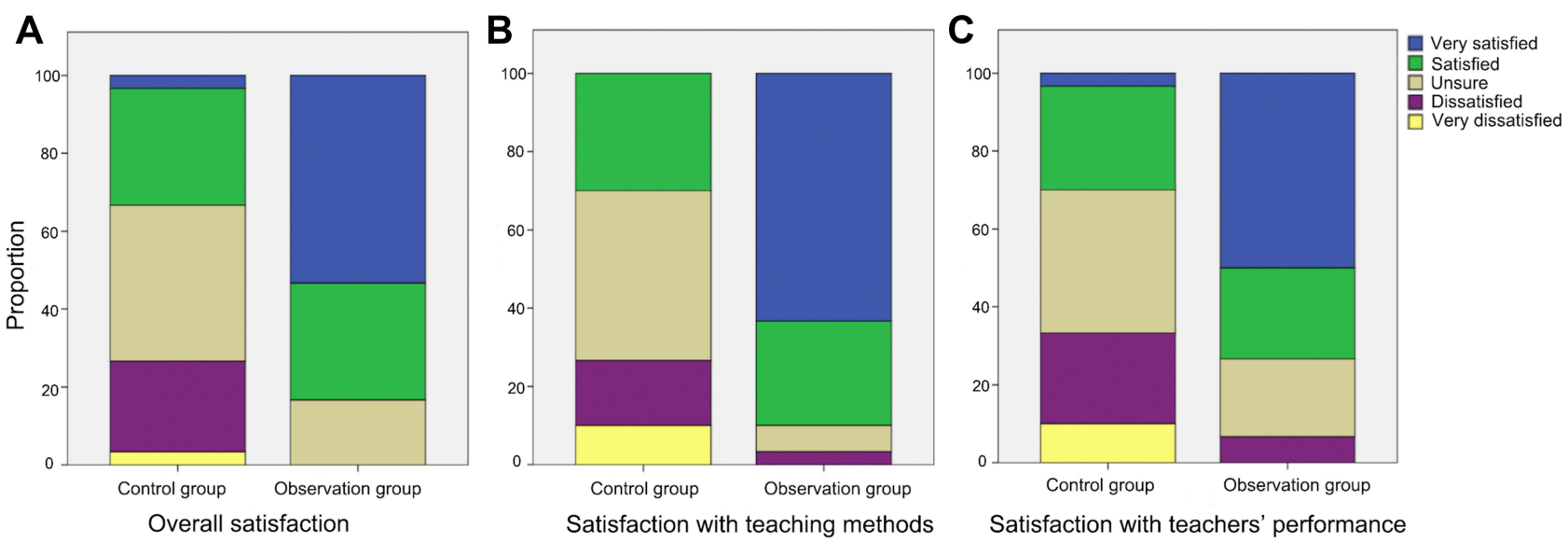

Figure 6 Comparison of student satisfaction between the two groups. (A) Proportion of different level of overall satisfaction in the control and observation groups; (B) Proportion of different level of satisfaction with teaching methods in the control and observation groups; (C) Proportion of different level of satisfaction with teachers' performance in the control and observation groups. 
ability and was rotated to reduce the impact of teaching differences between different faculty members on the final results of the study. In addition, Regarding the sample size calculation, due to the fact that seminars and CBL teaching methods are not popular among Chinese colleges, we are lack of experience and references to calculate the precise sample size. Besides, due to the influence of COVID-19, we only reach a sample size of 60 individuals after 2 years of research. Upon referring to related studies, ${ }^{14,20}$ we found their sample size were mostly around $60-80$. Therefore, we believe that a sample size of 60 individuals is appropriate for this study.

\section{Conclusion}

In summary, the combination of seminars and CBL teaching approach could be a better option over the traditional LBL in teaching cancer pain during medical oncology internship. Through the optimization of teaching scenarios, continuous improvement of teaching structures and teaching skills, the combined teaching approach of seminars and CBL will play an important role in the training of oncology students upon broader implementation in other curricula.

\section{Glossary}

\section{Seminar Teaching Method}

The seminar teaching method is a two-way teaching model in which students learn in small groups under the guidance of the instructor and discuss assigned problems and issues. The basic goal of the seminar method is to enable students to learn by discussing practical issues.

\section{Case-Based Learning (CBL)}

A student-centered, inquiry-based, patient-oriented teaching method designed to prepare students for clinical practice through real-life clinical cases. These cases provide a link between theory and practice through the application of knowledge to the case.

\section{Lecture-Based Learning (LBL)}

Lecture-based learning (LBL) is a kind of traditional teaching method based on teacher lectures that emphasize the mastery of theoretical knowledge.

\section{Acknowledgments}

We would like to thank the colleagues of the Department of Medical Oncology of our institution, and all the intern medical and nursing students that participated in this study.

\section{Funding}

This work was supported by the 512 Talent Cultivation Plan of Bengbu Medical College (by51202208), the Project of Research and Innovation Team of Bengbu Medical College (No. BYKC201908) and the Science Fund for Distinguished Young Scholars of the First Affiliated Hospital of Bengbu Medical College (No. 2019byyfyjq02).

\section{Disclosure}

The authors report no conflicts of interest in this work.

\section{References}

1. Russo MM, Sundaramurthi T. An overview of cancer pain: epidemiology and pathophysiology. Semin Oncol Nurs. 2019;35 (3):223-228. doi:10.1016/j.soncn.2019.04.002

2. Portenoy RK, Ahmed E. Cancer pain syndromes. Hematol Oncol Clin North Am. 2018;32(3):371-386. doi:10.1016/j.hoc.2018.01.002

3. Kaki AM. Medical students' knowledge and attitude toward cancer pain management in Saudi Arabia. Saudi Med J. 2011;32 (6):628-632.

4. Shahnazi H, Saryazdi H, Sharifirad G, Hasanzadeh A, Charkazi A, Moodi M. The survey of nurse's knowledge and attitude toward cancer pain management: application of health belief model. $J$ Educ Health Promot. 2012;1:15. doi:10.4103/2277-9531.98573

5. Lui L, So W, Fong D. Knowledge and attitudes regarding pain management among nurses in Hong Kong medical units. J Clin Nurs. 2010;17 (15):2014-2021. doi:10.1111/j.1365-2702.2007.02183.x

6. Sloan PA, LaFountain P, Plymale M, Johnson M, Snapp J, Sloan DA. Cancer pain education for medical students: the development of a short course on CD-ROM. Pain Med. 2002;3(1):66-72. doi:10.1046/j.1526-4637.2002.02009.x

7. Nimmaanrat S, Oofuvong M. Attitudes of medical students regarding cancer pain management: comparison between pre- and post-lecture test findings. Asian Pacific $J$ Cancer Prevention. 2015;16 (17):7453-7456. doi:10.7314/apjcp.2015.16.17.7453

8. Nimmaanrat S, Prechawai C, Phungrassami T. Cancer pain and its management: a survey on interns' knowledge, attitudes and barriers. Palliative Care Res Treatment. 2010;4:117822421000400001. doi:10.1177/117822421000400001

9. Zeng HL, Chen DX, Li Q, Wang XY. Effects of seminar teaching method versus lecture-based learning in medical education: a meta-analysis of randomized controlled trials. Med Teach. 2020;42 (12):1343-1349. doi:10.1080/0142159X.2020.1805100

10. Morgan R. Using seminars as a teaching method in undergraduate nurse education. Br J Nurs. 2019;28(6):374-376. doi:10.12968/ bjon.2019.28.6.374

11. Spruijt A, Wolfhagen I, Bok H, et al. Teachers' perceptions of aspects affecting seminar learning: a qualitative study. BMC Med Educ. 2013;13:22. doi:10.1186/1472-6920-13-22

12. Worth N. Experimenting with student-led seminars. Planet. 2013;27 (2):30-35. doi:10.11120/plan.2013.00003

13. Dewsbury BM, Reid A, Weeks O. Confluence: a seminar series as a teaching tool. $J$ Microbiol Biol Educ. 2013;14(2):258-259. doi:10.1128/jmbe.v14i2.595

14. Bi M, Zhao Z, Yang J, Wang Y. Comparison of case-based learning and traditional method in teaching postgraduate students of medical oncology. Med Teach. 2019;41(10):1124-1128. doi:10.1080/ 0142159X.2019.1617414 
15. McLean SF. Case-based learning and its application in medical and health-care fields: a review of worldwide literature. J Med Educ Curric Dev. 2016;JMECD-S20377. doi:10.4137/JMECD.S20377

16. Thistlethwaite JE, Davies D, Ekeocha S, et al. The effectiveness of case-based learning in health professional education. A BEME systematic review: BEME Guide No. 23. Med Teach. 2012;34(6):e421e44. doi:10.3109/0142159X.2012.680939

17. Zhang LL, Zhang Y, Meng FL, et al. Modeling and its application of seminar of case teaching method in the teaching of clinical oncology. Northwest Med Edu. 2014;22(6):1218-1220.
18. National Health Commission of the People's Republic of China. Cancer pain diagnosis and treatment specification (2018 edition). Chinese Clin Oncol. 2018;023(010):937-944.

19. Liu C, Wu X. Application effect of CBL combined with seminar teaching mode in clinical teaching of critical medicine. Chinese J General Practice. 2020;18(7):1214-1216, 1233. doi:10.16766/j. cnki.issn.1674-4152.001468

20. Zhang Q, Huang Y, Qin K, et al. Application of seminar teaching method combined with case-based learning in cancer rehabilitation teaching. Chinese J Rehabil. 2020;035(004):221-224.

\section{Publish your work in this journal}

The Journal of Pain Research is an international, peer reviewed, open access, online journal that welcomes laboratory and clinical findings in the fields of pain research and the prevention and management of pain. Original research, reviews, symposium reports, hypothesis formation and commentaries are all considered for publication. The manuscript

Submit your manuscript here: https://www.dovepress.com/journal-of-pain-research-journal management system is completely online and includes a very quick and fair peer-review system, which is all easy to use. Visit http:// www.dovepress.com/testimonials.php to read real quotes from published authors. 